\title{
MiniCSS: a software application to optimize crop irrigation and nitrogen fertilization strategies
}

\author{
Alvaro Rocca, Francesco Danuso \\ Department of Agricultural and Environmental Sciences, University of Udine, Italy
}

\begin{abstract}
Water resources are limited and agricultural input costs are steadily increasing; moreover, precipitation seems to be decreasing in amount or, at least, received in a more irregular manner.

Correctly deciding irrigation and fertilization amount and time implies to simultaneously consider phenological and nutritional crop status, weather pattern during the irrigation season and taking into account the economic and energy budgets. To treat all these complexities, the use of crop simulation models is particularly indicated. Models are strictly connected to academic and research contexts and have not wide-melted farmers and agricultural technicians, despite they are strongly encouraged to optimize the use of water and fertilizer MiniCSS, a software for the optimization of irrigation and nitrogen (N) fertilization by simulation is here presented. Its primary aim is to be easy to use, thanks to a reduced number of input parameters and a user-friendly dialog window. MiniCSS can perform i) annual/multiannual simulations, ii) simulation experiments by varying irrigation and fertilization intensity, iii) calibration of the model parameters and iv) optimization of other cultural practices. Textual and graphical results are reported as daily values, annual averages, cumulative probability and dose-response curves.
\end{abstract}

\section{Introduction}

It is commonly recognized that water resources are limited and, at the same time, the agricultural input costs (in monetary and energetic terms) are steadily increasing. Furthermore, due to climatic changes,

Correspondence: Francesco Danuso, Department of Agricultural and Environmental Sciences, University of Udine, via delle Scienze 208, 33100 Udine, Italy. Tel. +39.0432 .558614 - Fax: +39.0342 .558603 .

E-mail: francesco.danuso@uniud.it

Key words: optimisation, irrigation, fertilization, simulation, crop, model, decision support system.

Received for publication: 11 October 2010.

Accepted for publication: 8 March 2011.

(C) Copyright A. Rocca and F. Danuso, 2011

Licensee PAGEPress, Italy

Italian Journal of Agronomy 2011; 6:e13

doi:10.4081/ija.2011.e13

This article is distributed under the terms of the Creative Commons Attribution Noncommercial License (by-nc 3.0) which permits any noncommercial use, distribution, and reproduction in any medium, provided the original author(s) and source are credited. precipitation seems to be decreasing in amount or, at least, received in a more irregular manner than in the past. From the other hand, civil and industrial water demand is growing, especially in developing countries (Acutis et al., 2010).

Correctly deciding the amount and time of irrigation and fertilization of agricultural crops is a difficult task, since the decider must consider phenological and nutritional crop status, forecast the weather pattern during the irrigation season and take into account the economic and energy budgets of the farm. To be able to treat all these complexities in an integrate way the use of crop simulation models is particularly indicated. These can be used as decision support tools for the management of cropping system, for the optimization of the cultural practices and to take decisions like planting date, cultivar selection, fertilization, or water and pesticides usage (Steduto et al., 2009) but also for strategic aims.

Several authors have proposed simulation models to optimize crop irrigation (Danuso et al., 1995, Bergez et al., 2002; Acutis et al., 2010) and nitrogen (N) fertilization (Makowski et al., 1999). Most of these models have a very complex structure and require specific skills and long training period for a correct use. Moreover, the typical crop model needs a long time for a good parameterization and calibration. Therefore, the use of many models is strictly connected to academic and research contexts and have not wide-melted farmers and agricultural technicians, despite farmers are strongly encouraged to optimize the use of water and fertilizer and technicians are called to assist farmers with the responsibility of protecting the environment.

This paper presents MiniCSS, a software application for the optimization of irrigation and nitrogen fertilization by simulation, developed with the primary aim to avoid these drawbacks by reducing to a minimum the requests to the users. This goal has been pursued with a reduced number of input parameters and with a user-friendly dialog window. As in other cases (Steduto et al., 2009), the intention was to maintain an equilibrium among accuracy, simplicity and robustness.

\section{Materials and Methods}

The MiniCSS application is formed by three components: i) the crop model simulation engine CSSmini; ii) a database of crop and soil parameters that can be selected or updated by the user; iii) the graphical user interface of the application (MiniCSS itself).

The implementation methodology of MiniCSS (Figure 1) has been carried out by developing two different and parallel work plans: the simulation engine and the user application.

The first involved the creation of a simple but robust crop simulation model to be used as calculation engine (CSSmini). This is a generic, daily step crop simulation model derived from the Cropping System Simulator (CSS) (Danuso et al., 1999) and kept deliberately simple in order to facilitate its practical application.

The second task was the development of a simply to use graphical interface (MiniCSS), that allows the user setting up the input data 
requested by the model and summarizing the simulation results. Moreover, it allows the optimisation of irrigation and fertilization strategies by simulation experiments to create the dose-response curves. Parameters can be manually or automatically (with the GaussNewton algorithm) calibrated and simulated data can be graphically compared with the observed ones.

The model can use historical meteorological data or can generate syntetic meteo series by the Climak weather generator (Danuso, 2002), already implemented in the installation package. Meteorological data can be checked or rebuilt by proper procedures. MiniCSS runs CSSmini as a separate executable, preparing the input files; after simulation, it reads and automatically post-processes simulation results.

This double way implementation allows an easy and independent updating of the CSSmini model, without modifying the main functions of MiniCSS that remains with the same familiar graphical interface.

\section{Model overview}

CSSmini has been developed using SEMoLa (Simple, Easy-to-use, Modelling Language; Danuso, 2003), a software application for the development of simulation models and agro-ecological knowledge integration. SEMoLa allows the simulation of dynamic systems by the construction of deterministic and stochastic models, based on states (stock and flow) or on elements (Individual Based Modelling). The ontology of SEMola originated from the system dynamics approach, proposed by Forrester (1961), widely used in describing continuous systems (Muetzelfeldt and Massheder, 2003). A SEMoLa model is a text file, written with a declarative language, easy to understand and modify, that, after translation and compilation, becomes an executable file.

CSSmini has a modular structure (Figure 2). Each module represents a different part of the cropping system. Besides the main module (CSSmini) connecting all the others, there are modules for phenology and crop growth (CSSmini_crop), soil dynamics (CSSmini_soil), water balance (CSSmini_water), soil organic matter dynamics (CSSmini_som), soil nitrogen (CSSmini_nitrogen) and the cropping practices (CSSmini_manag). Furthermore, an economic budget module has been developed (CSSmini_economy), which considers yield, market prices of products and costs for irrigation and fertilization.

i) CSSmini_soil describes the physical characteristics of the soil such as water field capacity, wilting point and maximum water capacity; all this parameter are corrected for the gravel percentage of the soil. In addition, the module simulates the increase of soil depth as a function of the root deepening, sinchronized to the epigeal development.

ii) CSSmini_water, carries out, with a mono-layer cascade approach, the simulation of soil water content, considering maximum (ETm) and actual (ETa) evapotranspiration, runoff, infiltration, percolation and drainage into groundwater. ETa depends on the actual volumetric soil moisture $(U s)$. The soil water reserve, increase with rainfall and irrigation. The maximum evapotranspiration $(E T m)$ is calculated as $E T m=K c \cdot E T r$, where $K c$ is the crop coefficient for the loss of water, according to the phenological stage (Allen et al. 1998) and $E T r$ is the reference evapotranspiration.

iii) CSSmini_som simulates the dynamics of soil organic matter with an implementation of the RothC model (Coleman et al., 2008). This module divides soil organic matter into easily decomposable residues, resistant to decomposition residues, humus and microbial biomass, with specific mineralization coefficients.

iv) CSSmini_nitrogen simulates the nitrogen dynamics of soil, considering the fractions of nitrogen as nitrate $\left(\mathrm{NO}_{3}{ }^{-}\right)$and ammonium $\left(\mathrm{NH}_{4}{ }^{+}\right)$. Ammonium is considered as $\mathrm{NH}_{4}{ }^{+}$in solution and adsorbed on soil colloids. In the nitrification process, only the $\mathrm{NH}_{4}{ }^{+}$ in solution is involved. The nitrate is absorbed by plants or leached to groundwater. The concentration of $\mathrm{NH}_{4}{ }^{+}$in the soil can increase due to the mineralization of soil organic matter or to nitrogen fertilizations.

v) CSSmini_crop simulates the phenological development by the growing degree days $(G D D)$, calculated as the difference between the mean daily air temperature and the base temperature. This module also simulates the biomass accumulation and crop yield using the radiation use efficiency $(R U E)$ approach. Moreover, the model considers the reduction of the maximum rate of growth in the presence of stress conditions (non-optimal temperature, water shortage and lack of nitrogen).

The water stress factor $(F w s)$ tends to zero for soil moisture $(U s)$ close to the wilting point $(W P), 1$ for $U s$ higher than the critical soil moisture $(U z)$ and $F w s=(U s-W P) /(U z-W P)$ for intermediate values. $\mathrm{Uz}$ is the critical soil moisture for beginning of drought stress, calculated as:

$$
U z=W P+(F C-W P) \cdot(1-Z)
$$

where:

$W P=$ soil moisture at wilting point, corrected for the amount of gravel;

$F C=$ soil moisture at field capacity, corrected for the amount of gravel;

$Z=$ critical fraction of available water for stress, obtained with an empirical equation (Danuso et al., 1992) as a function of ETm.

The equation interpolates the tabular values reported by Doorembos

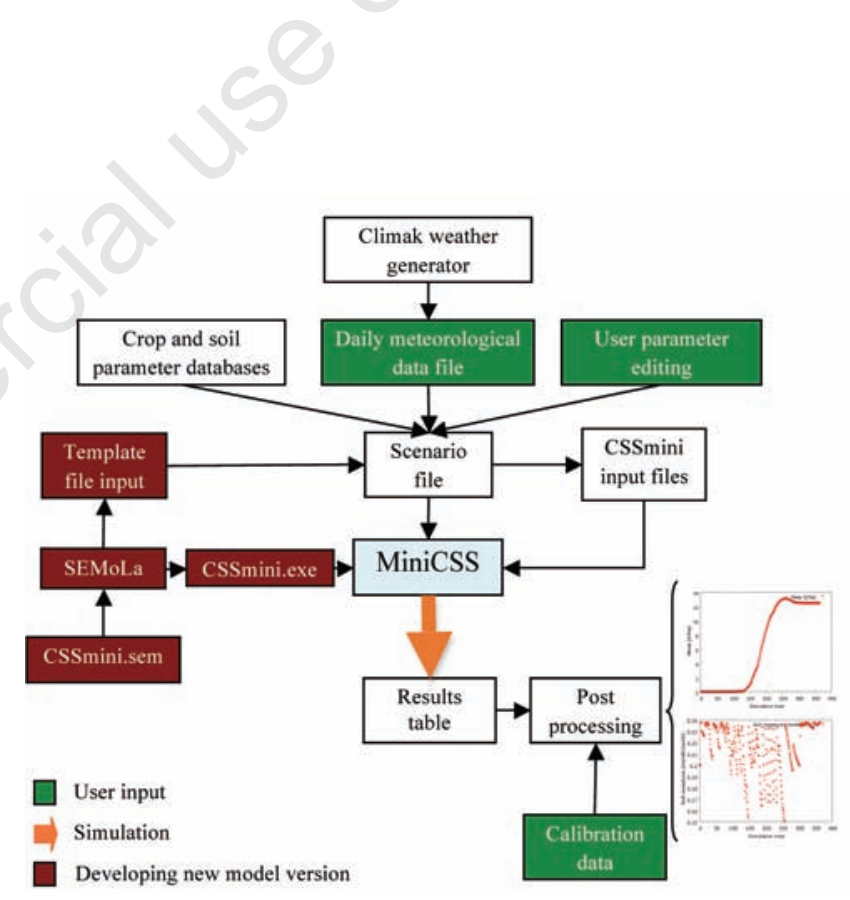

Figure 1. MiniCSS implementation methodology.

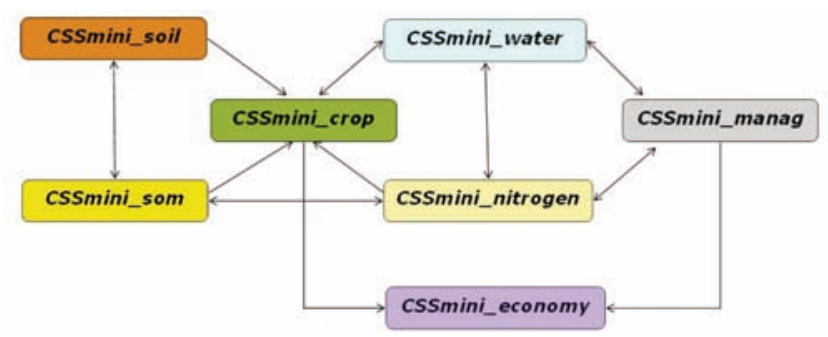

Figure 2. Modular structure of CSSmini. 
and Kassam (1986) for different crop groups (C1, C2 and C3 are empirical parameters):

$$
Z=1-\left(\frac{C 1}{1+C 2 \cdot e^{-C^{3} \cdot E^{\prime 2 !} \cdot \pi}}\right)
$$

The correction factor for the nitrogen stress on growth rate $(F N)$ is a linear function that depends on the nitrogen content of the crop. $F N$ is 1 (no stress) when $\mathrm{N}$ concentration in crop is at his optimum and decrease linearly till zero (maximum stress).

The total crop yield (grain or other useful products) is determined by the harvest index parameter $(H I)$, applied to the total biomass production.

vi) CSSmini_manag. This module simulates the cropping practices (sowing, irrigation, fertilization) as events that can be automatically generated using a decisional strategy or scheduled by the user. The scheduled cropping practices (sowing, irrigations and nitrogen fertilizations) have to be inserted by the user indicating their dates and amounts. For the automatic practices, instead, the module uses information from other modules (temperature, phenological stage, water and nutritional stress index, etc.) for the decisions. Automatic sowing is based on mean air temperature values: when the daily mean temperature is greater than the crop base temperature for more than 3 consecutive days, the crop will be sown. For the automatic irrigation, a parameter of allowed stress level $(K d w)$ is used, in order to calculate the critical soil moisture for irrigation (Uirri). When the actual soil moisture $(U s)$ became smaller than Uirri, the irrigation will be performed.

$$
\text { Uirri }=W P+(U z-W P) \cdot(1-K w)
$$

Increasing $K d w$ determines a smaller Uirri so less irrigation events will be applied. The irrigation water volume is calculated as the amount of water needed to bring the soil moisture to field capacity for the current soil rooting depth. The automatic $\mathrm{N}$ fertilization uses the same criteria of the automatic irrigation: a parameter of allowed nutritional stress $(K d n)$ is used. When FN is smaller than $K d n$ the automatic fertilization will be performed. The amount of nitrogen fertilizer is defined by a parameter inserted by the user. Both automatic irrigation and fertilization allow the crop to growth without stress, providing the maximum biomass accumulation, depending on temperature and radiation regimes.

vii) CSSmini_economy. This module simulates the crop economic budget, considering the fixed cost for each irrigation and variable costs depending on the amount of water applied; the costs of the fertilizer unit and for the distribution were also considered. The incomes are obtained from the simulated yield, the market price of the product and, possibly, the monetary subsides.

\section{Application description}

MiniCss (Figure 3) is a software application with a graphical interface; its main aim is to simplify the use of the crop simulation model CSSmini. It can perform the optimization of irrigation and nutrition strategies throughout dynamic simulation. In this case, optimization is intended as the determination of times and amounts of water and nitrogen distributions, finalized to the maximization of crop responses, according to productive and economic criteria.

The calculation engine (CSSmini.exe) can be easily modified, improved, rebuilt and tested using the SEMoLa framework (Figure 1); calculation algorithms can be changed without the need to create a new graphical interface. This feature can be important for the on-line update of the model.

At present, MiniCSS may perform annual or multi-annual simulations but not yet for crop rotation. By screen choices the user can cre- ate the cropping scenario, which contains all the needed information for the calculation procedures. The scenario is tailored by selecting standard crop and soil parameters, meteorological data files and from other screen choices made by the user.

\section{The cropping scenario}

The scenario is a text file that set up the simulation: the program, by interacting directly with the screen choices, meteorological data, crop and soil parameters, automatically generates a simulation file (simfile) that specifies the simulation type (simple or multiple). In this way it is possible to create different complex simulations combining crop and soil parameters, meteorological data and cultural practices.

The scenario file is created by integrating four different types of information:

i) Meteorological daily data; the daily meteorological data required are mean temperature $\left({ }^{\circ} \mathrm{C}\right)$, rainfall $(\mathrm{mm} / \mathrm{d})$, solar radiation $\left(\mathrm{MJ} / \mathrm{m}^{2} / \mathrm{d}\right)$, reference evapotranspiration $(\mathrm{mm} / \mathrm{d})$. A meteorological data file can have one or more years of data; the number of dataset in the meteo file determines the number of simulations to be run. In this way the program will set up, automatically, a simple or a multi-annual simulation. Meteorological data can be prepared by the user in different formats: SEMola database dctfile (dct), Dbase (dbf) or comma separated value (csv). The last two can be directly created also from a spreadsheet application. MiniCSS has many options for the check and the rebuilding of data in meteorological files: it assists the user in the creation of correct meteorological data file by automatic correction of the names of variables, changes the date format, and rebuild missing data. It also advises when the file is not correct for missing days, wrong time order and data out of range. Meteorological data can be also generated by the Climak weather generator

ii) Crop parameter database; selecting a crop (maize, soybean, sunflower, wheat, etc.) all the crop parameters are set. The most sensitive parameters are displayed on the screen to be customized by the user. The other crop parameters not displayed on the main window of the application, can be also edited or used to create custom sets of crop parameters for new crops or for specific uses (for example, to modify crop parameters for existing crop, after calibration).

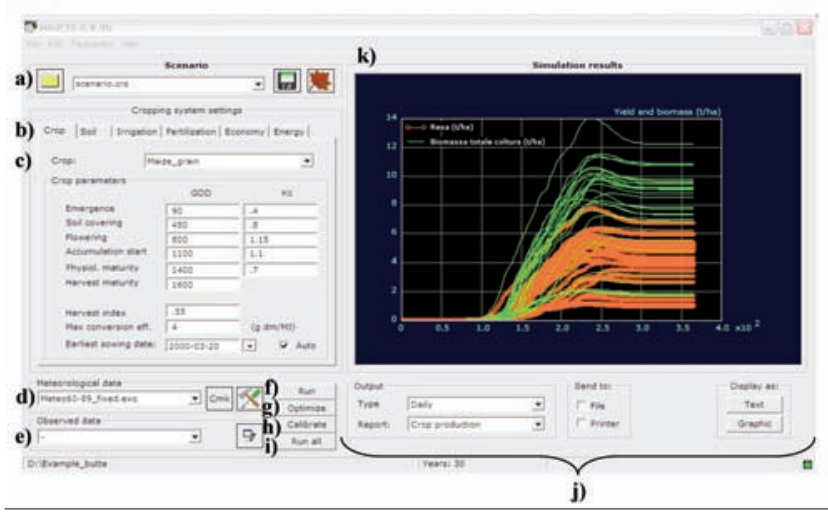

Figure 3. The MiniCss application: a) sets, saves and deletes scenario files; $b$ ) selects the type of information to set (crop, soil, irrigation, fertilization and budget); c) sets and loads crop parameters; d) sets, loads, edits, fixes and generates meteorological data files; e) sets and loads data files for calibration; f) runs simulation; g) optimization; h) automatic calibration; i) runs all scenarios for comparison; j) defines how to display results (text or graphic), the result type (daily, annual, cumulated probability, response curves) and the specific report. Text or graphic results can be also printed or saved; $k$ ) result window switching between text and graphic format. 
iii) Soil parameter database; in the same way as the crop parameters, by selecting a soil type, all its parameters are set, again showing the most sensitive to be edited. To be able to modify also the less important soil parameter, a specific window has to be open.

iv) Crop management choices: automatic or manual sowing; automatic, scheduling or fixed-date irrigation; automatic or scheduling fertilization; sowing, irrigation and fertilization dates and amount.

\section{The simulation}

The main uses of MiniCSS are the annual/multi-annual simulation, the definition of the irrigation and fertilization intensity (automatic or manual), the calibration of parameters and the optimization of the crop practices.

i) Annual and multi-annual simulation; depending on the meteorological data file selected, the simulation can be annual (Figure 4) or multi-annual (Figure 5). If the meteorological data file contains more than one data set (one for each year) the simulation will be multi-annual. This kind of simulation permits the estimation of the not-exceeding probability curve for the irrigation volume requirement, depending on climate variability.

ii) Automatic and manual setting of cropping practices; the simulation can be set up with automatic or manual irrigation and/or fertilization. Automatic application is used to maintain the crop yield production to the maximum, so it is possible to obtain information about irrigation and nitrogen needs of the crop. Using the automatic cropping practices and a multi-annual simulation it is possible to probabilistically calculate the length of the irrigation season, irrigation water volume and nutritional crop requirements. The sec-

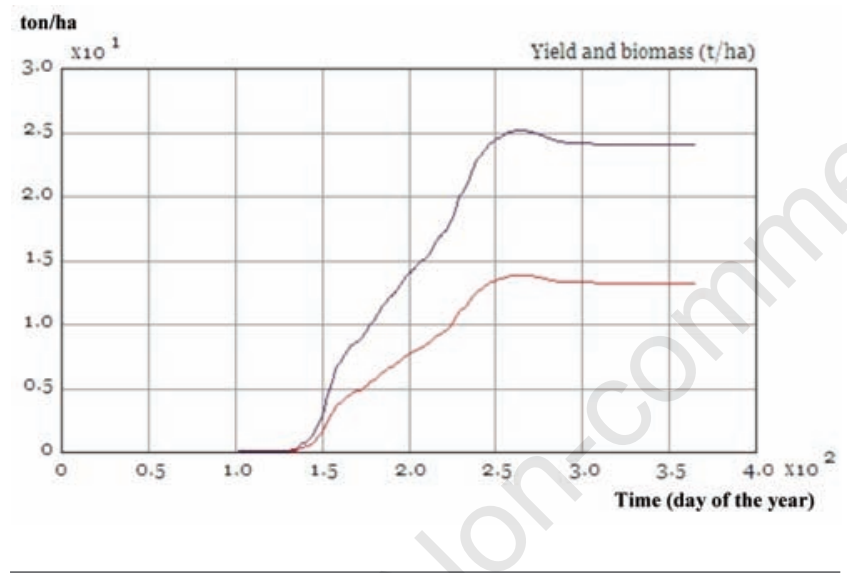

Figure 4. Crop yield and biomass from an annual simulation.

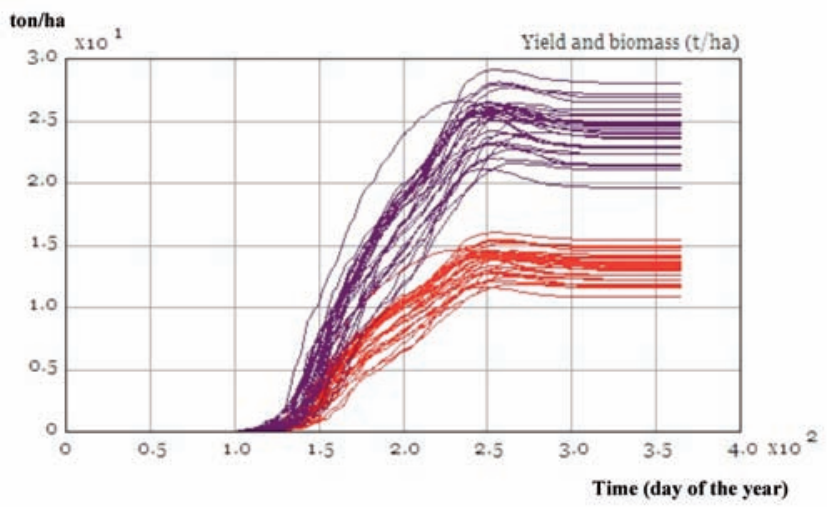

Figure 5. Crop yield and biomass from a multi-annual simulation. ond approach of simulation provides a method for scheduling irrigation and nitrogen fertilization, in specific dates and amount of water and nitrogen. This approach can be useful to apply a scenario analysis, in order to verify the behaviour of crops with real or hypothetical scenarios, or even with just the natural contributions. The manual setting of irrigation and fertilization is used also for parameter calibration, in order to compare the simulated results with the experimental data, considering the actual cropping practices.

iii) Parameter calibration; this procedure consists in a graphical comparison of the simulation result with the experimental ones and the parameter adjustment. New runs are repeated till to the reaching of the best fitting. Moreover it is possible to perform automatic calibration. The dataset used for calibration can be in the dct or csv format and must contain the time variable plus the observed variables. These have to have the same name of the simulated variables.

iv) Optimization; the optimization is performed by the execution of simulation experiments to obtain dose-response curves for annual irrigation water. The simulation is set to automatic sowing, irrigation and nitrogen fertilization. The model will perform a multiple simulation, generating different level of seasonal irrigation water by changing, for each simulation, the parameter of allowed water stress $K d w$, ranging from 1 (max stress allowed) to 0 (no stress allowed). The same approach is adopted for $\mathrm{N}$ fertilization.

\section{Results}

\section{The simulation result}

After simulation, MiniCSS generates a file containing the main simulated variables (yield, soil moisture, soil nitrogen, economic balance, total water and nitrogen distributed, etc.) reported as daily values, annual averages, and cumulative probability or dose-response curves. The results can be shown in a graphical or textual form, saved to a file or printed. Cumulative probability curve is calculated from the multi-annual simulation results; the simulation, performed on different years, reflects the effects of climatic variation on crop yield (Figure 5). From the cumulative curve it is possible to determine the beginning and the end of the crop period in which irrigation is required (irrigation season), its duration, both as average value or probability to exceed values (Figure 6).

Dose-response curve to irrigation volume are obtained performing a simulation experiment in which irrigation is applied with relation to the acceptable water stress $(K d w)$. MiniCSS makes twelve simula-

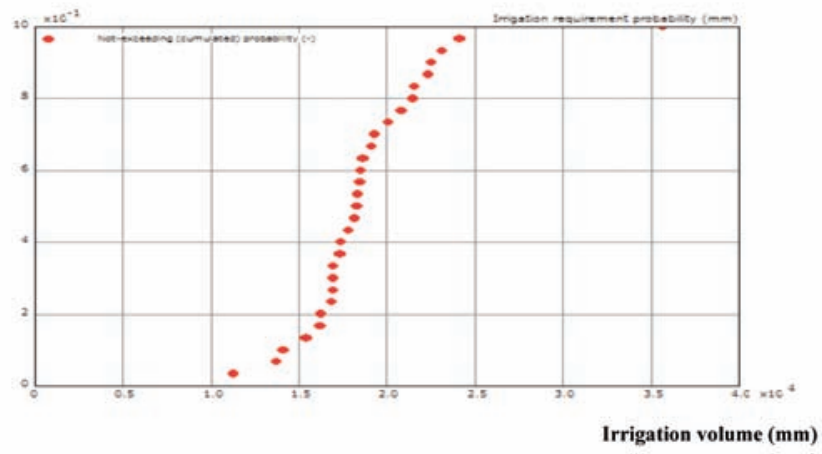

Figure 6. Evaluation of the irrigation requirement by the notexceeding probability curve. 
tions, using different values of $K d w$, ranging from 0 to 1 , so obtaining different levels of seasonal irrigation volume. The dose-response curve can be obtained for the yield (Figure 7), but also for the total crop net profit. Figure 8 shows an example of dose-response curve for the crop incomes in a typical configuration of crop costs and revenues.

\section{Model parameterization and calibration}

In this work, CSSmini model has been preliminary parameterized for sunflower (Helianthus annum L.) by a trial-and-error procedure and and then calibrated using the MiniCSS automatic calibration routine. That utilizes an iterative procedure (Gauss-Newton linearization method; Beck and Arnold, 1977; Draper and Smith, 1981) for the minimisation of the residual sum of square between observed and simulated values. As a calibration example, pedo-climatic data and measured results for soil moisture, leaf area index and yield obtained from experimental trials conducted at Udine have been used.

\section{Experimental trials}

The experimental trials were carried out in 1987 at the Experimental Farm of the University of Udine (Udine, Italy, Lat. $46^{\circ} 2$ ' $49^{\prime \prime} \mathrm{N}$, Long. $\left.13^{\circ} 13^{\prime} 20^{\prime \prime} \mathrm{E}\right)$ at an altitude of $110 \mathrm{~m}$ a.s.l. The soil was medium-textured and with about $10 \%$ of gravel (Table 1).

The meteorological data were collected from the meteorological station of the farm. Experiments were carried out using the hybrid Florom 305 and with two irrigation schemes. The sunflower crop was preceded by maize. Agricultural practices have focused on the soil preparation with an autumn ploughing and a harrowing before planting. The sowing was carried out with a distance of $0.70 \mathrm{~m}$ between rows and $0.28 \mathrm{~m}$ between plants on the row. The sowing date was March $11^{\text {th }}, 1987$. Fertilization was done in two different periods: a pre-sowing fertilization with $60 \mathrm{~kg} / \mathrm{ha}$ of $\mathrm{N}$ and $120 \mathrm{~kg} / \mathrm{ha} \mathrm{P}_{2} \mathrm{O}_{5}$ and $\mathrm{K}_{2} \mathrm{O}$ and a second fertilization in coverage, with $80 \mathrm{~kg} / \mathrm{ha}$ of $\mathrm{N}$ (urea). The irrigation events and the water volumes are shown in Table 2 . Weekly measurements were made on soil moisture (with the gravimetric method, taking samples of $5 \mathrm{~cm}$ of soil at $25 \mathrm{~cm}$ depth) and on leaf area index (LAI). The final grain yield (t/ha) was also detected.

Table 1. Soil characteristics of the trials.

\begin{tabular}{lcc} 
& Unit \\
Soil maximum depth & $\mathrm{m}$ & 0.40 \\
Soil moisture at field capacity & $\%$ & 25.5 \\
\hline Soil moisture at wilting point & $\%$ & 10.5 \\
Maximum soil water content & $\%$ & 50 \\
\hline Sand & $\%$ & 42 \\
Clay & $\%$ & 18 \\
\hline Gravel & $\%$ & 10.5 \\
Soil organic matter & $\%$ & 2.39 \\
\hline
\end{tabular}

Table 2. Irrigation events and water volumes.

\begin{tabular}{cl}
\hline \multicolumn{1}{c}{ Date } & Volume \\
\hline July $3^{\text {rd }} 1987$ & $40 \mathrm{~mm}$ \\
\hline July $16^{\text {th }} 1987$ & $35 \mathrm{~mm}$ \\
\hline July $24^{\text {th }} 1987$ & $25 \mathrm{~mm}$ \\
\hline July $27^{\text {th }} 1987$ & $25 \mathrm{~mm}$ \\
\hline August $13^{\text {th }} 1987$ & $25 \mathrm{~mm}$ \\
\hline August $17^{\text {th }} 1987$ & $25 \mathrm{~mm}$ \\
\hline August $21^{\text {st }} 1987$ & $25 \mathrm{~mm}$ \\
\hline
\end{tabular}

\section{Model calibration results}

The model calibration for sunflower has been carried out using MiniCSS, starting with the database parameter values and setting sowing day, irrigation and fertilization as in the trials. As first, the soil parameters have been calibrated against the soil moisture (Figure 9), obtaining the best fit with the values reported in Table 3 .

After calibrating soil parameters, crop parameters for the leaf area index have been calibrated (Figure 10). The obtained values are report-

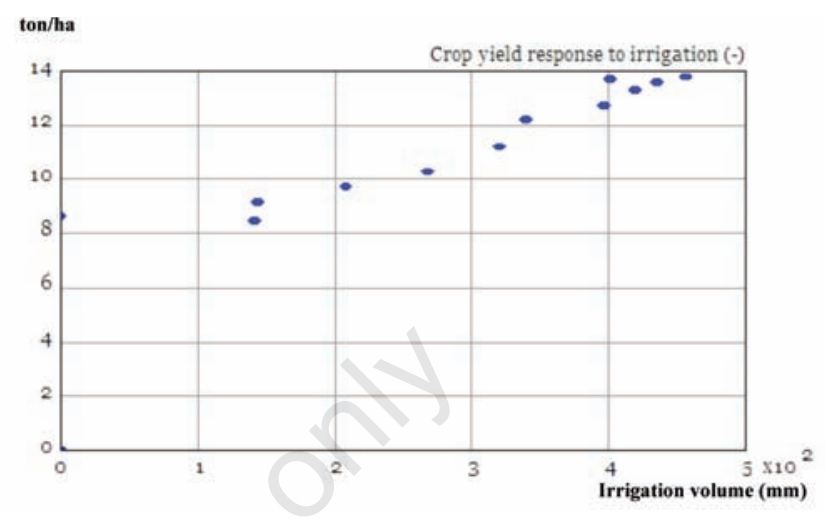

Figure 7. Dose-response curve to the seasonal irrigation volume for yield.

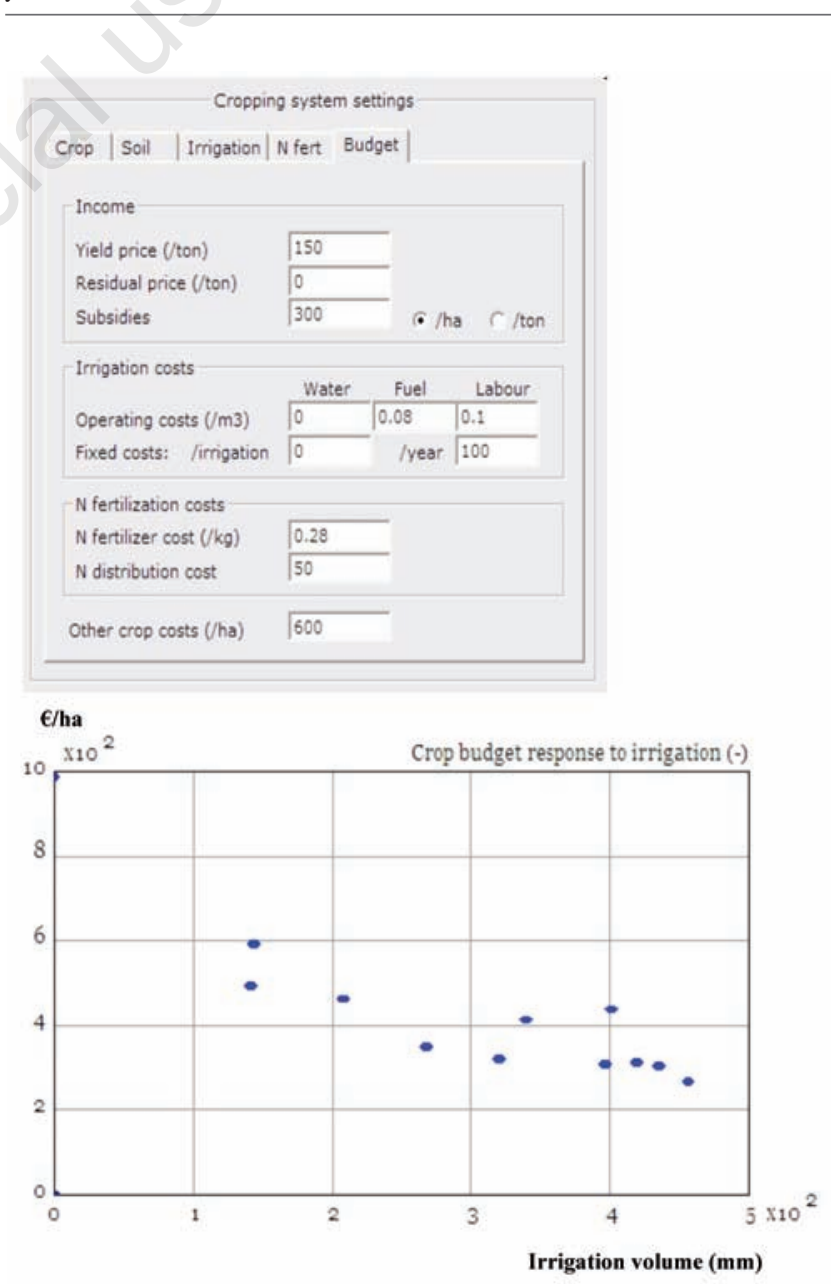

Figure 8. Dialog for economic crop budget configuration and a dose-response curve obtained. 
ed in Table 4.

In Figure 9 the soil moistures observed and simulated under rain-fed and irrigated conditions are reported. Graphically it is possible to notice a good correspondence between simulated and measured values. It can be remarked that the fitting was better in the rain fed treatments.

The leaf area index (Figure 10), despite the simplicity of the model, has been simulated quite satisfactorily. Furthermore, this good behavior indicates a correct representation of crop phenology and crop biomass accumulation, confirmed also by the simulation of the crop yield (Figure 11).

In Table 5, the most important statistics fot the model fitting (root mean square error, modelling efficiency, coefficient of determination, coefficient of residual mass, maximum absolute error, etc.) (Janssen and Heuberger, 1995) are reported. This table is automatically generated by MiniCSS after the calibration run.

\section{Conclusions}

The main purpose of the work was to produce a robust (even if simple) crop model to simulate yield response to water and nitrogen stress, for strategic and management decisions in agricultural systems. MiniCSS requires a small number of parameters and input variables to run simulations. Some of the model parameters have a clear meaning and are easy modifiable by the user; therefore, the model seems to be suitable for a broad range of users and management decisions.

The implementation of the weather generator Climak permits to evaluate the effect of climatic change and uncertainty on cropping systems. In fact, MiniCSS can be a used to evaluate irrigation and nutri-
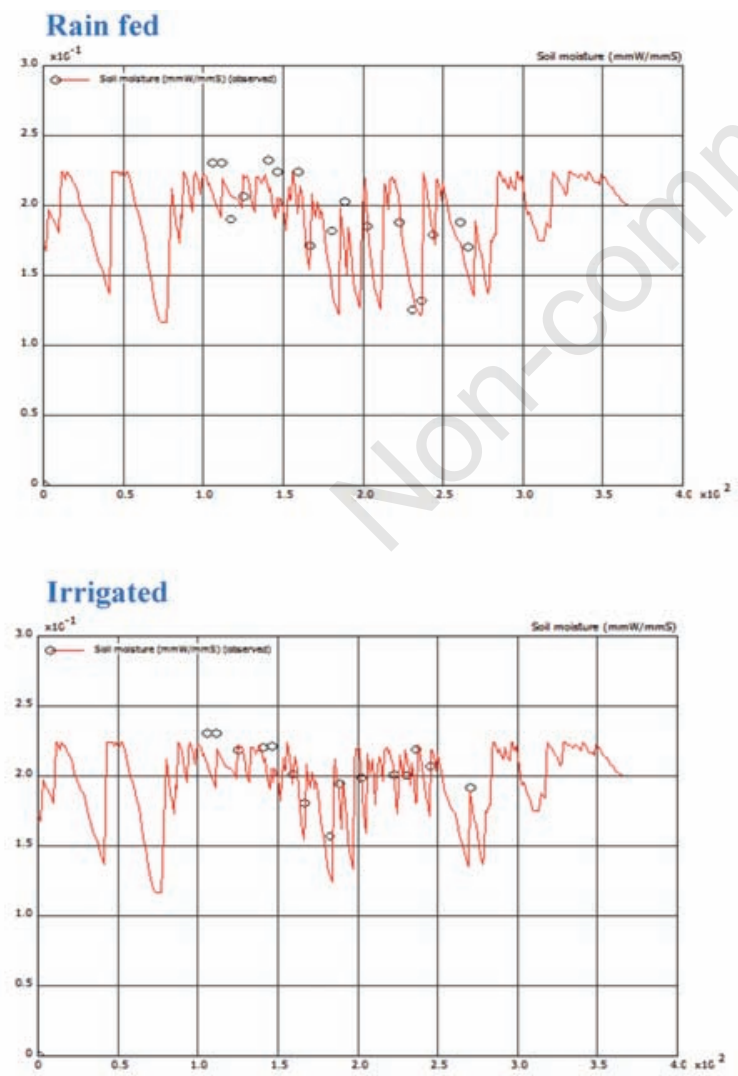

Figure 9. Soil moisture. Solid line represents simulation result, dots represent measured data. tional scenarios, using the automatic cropping practices and a multiannual simulation; it calculates also probabilities (considering climatic variability) for the length of the irrigation season, the irrigation water volume and nutritional needs of the crop. Furthermore, the program allows the optimization of the system by simulation experiments

Table 3. Soil parameters as calibrated for soil moisture.

\begin{tabular}{llcc} 
Parameter & Description & $\begin{array}{c}\text { Value } \\
\text { after } \\
\text { calibration }\end{array}$ & Unit \\
Sand & Soil sand content & 65 & $\%$ \\
Clay & Soil clay content & 12 & $\%$ \\
\hline MWC & Maximum water capacity & 0.45 & $\mathrm{mmW} / \mathrm{mmS}$ \\
FC & Water at field capacity & 0.25 & $\mathrm{mmW} / \mathrm{mmS}$ \\
\hline$W P$ & Water at wilting point & 0.13 & $\mathrm{mmW} / \mathrm{mmS}$ \\
KS & Saturated conductivity & 600 & $\mathrm{mmW} / \mathrm{d}$ \\
\hline Gravel & Soil gravel amount & 10.5 & $\%$ \\
Dsmax & Maximum soil depth & 400 & $\mathrm{mmS}$ \\
\hline OM & Soil organic matter & 2.5 & $\%$ \\
\hline
\end{tabular}

$\mathrm{mmW}, \mathrm{mm}$ of water; $\mathrm{mmS}$, mm of soil.

Table 4. Crop parameters for sunflower, after calibration on leaf area index.

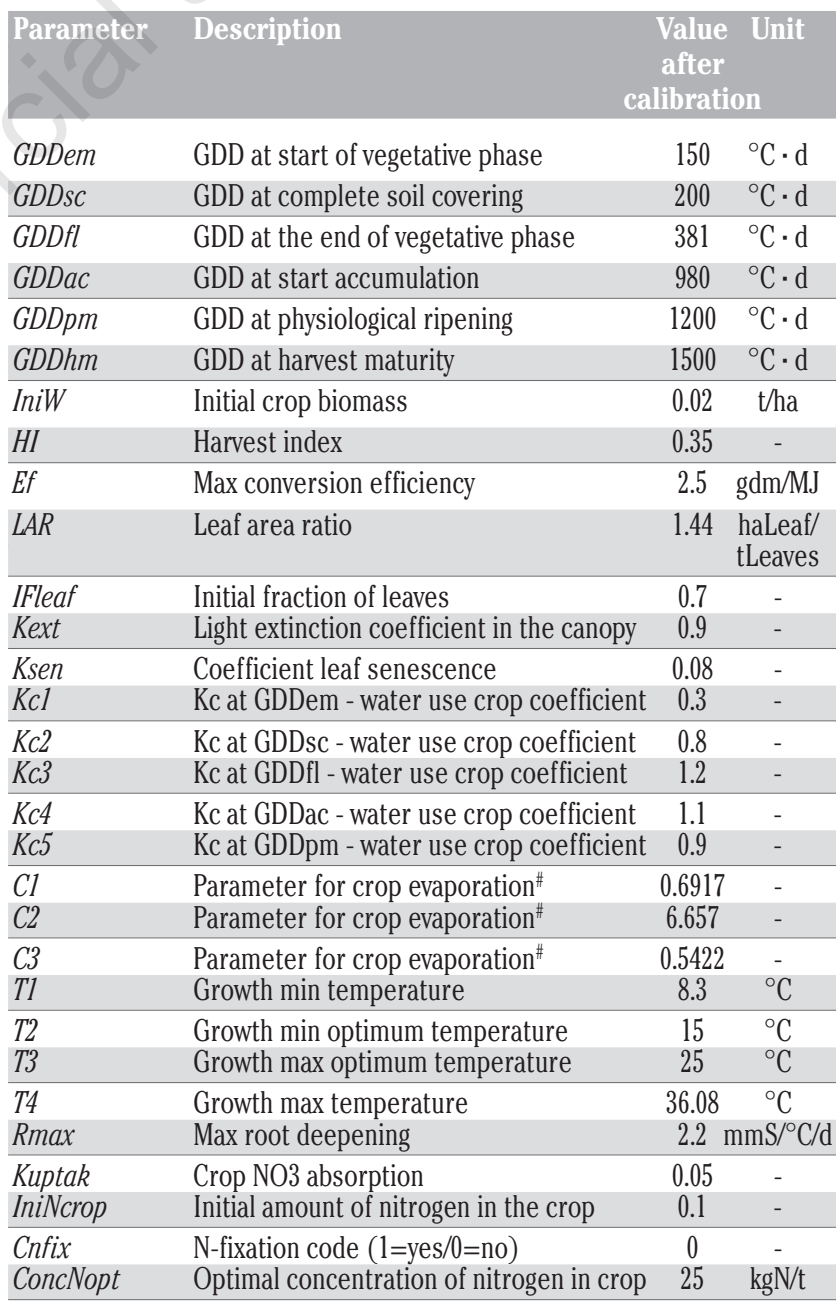

GDD, growing degree days; kc, crop coefficient. "Danuso et al. 2002. 
Rain fed

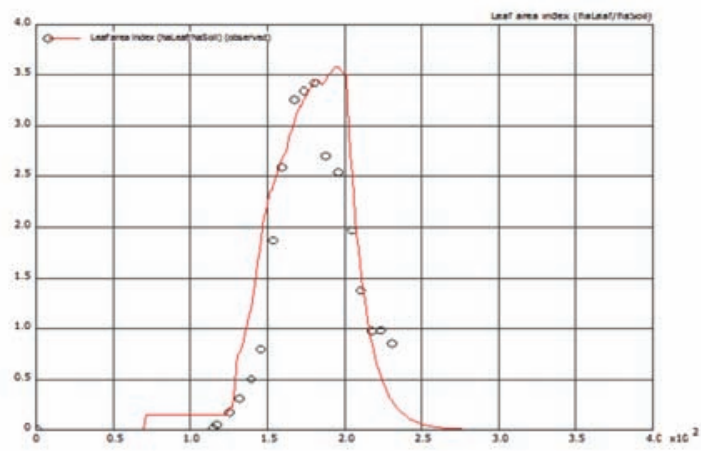

Irrigated

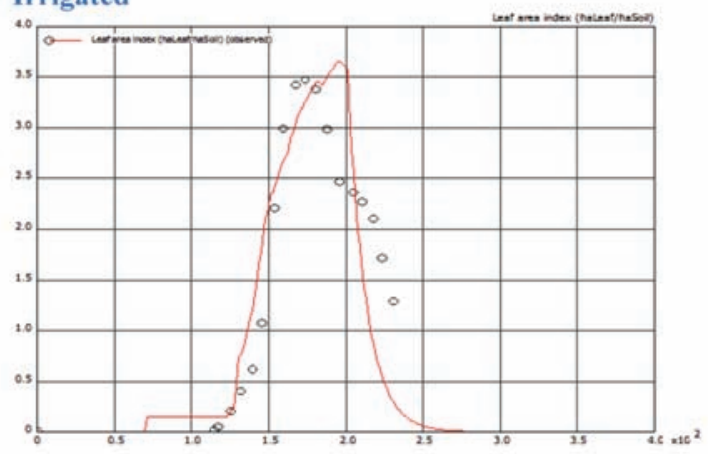

Figure 10. Leaf area index (LAI). Solid line represents simulation, dots represent measured data.
Rain fed

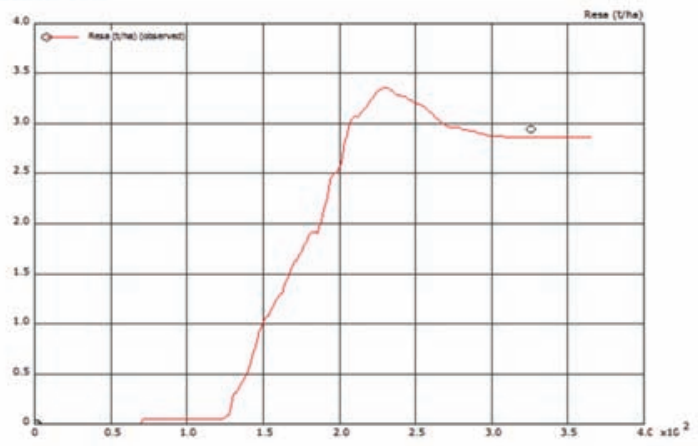

Irrigated

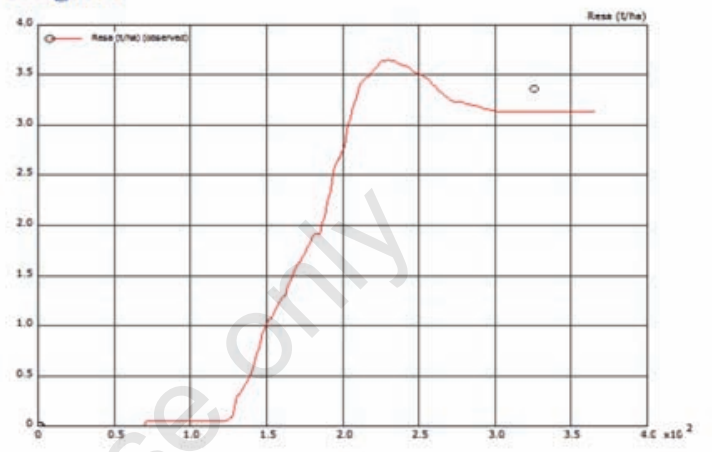

Figure 11. Yield (t/ha). Solid line represents simulation, dots represent measured data.

Table 5. Statistics of fitting for soil moisture and leaf area index, in rain fed and irrigated conditions, as generated by MiniCSS.

\begin{tabular}{|c|c|c|c|c|}
\hline $\begin{array}{l}\text { Comparison variable } \\
\text { Number of observations }\end{array}$ & $\begin{array}{l}\text { Rain fed } \\
\text { Soil moisture } \\
\text { (Us) } \\
17\end{array}$ & $\begin{array}{l}\text { Rain fed } \\
\text { Leaf area index } \\
\text { (LAI) } \\
18\end{array}$ & $\begin{array}{l}\text { Irrigated } \\
\text { Soil moisture } \\
\text { (Us) } \\
15\end{array}$ & $\begin{array}{l}\text { Irrigated } \\
\text { Leaf area index } \\
\text { (LAI) } \\
18\end{array}$ \\
\hline Bias & & & & \\
\hline Average error (mean bias error) (AE) & -0.008 & 0.247 & -0.012 & -0.036 \\
\hline Coefficient of residual mass (CRM) & 0.044 & -0.161 & 0.058 & 0.020 \\
\hline $\begin{array}{l}\text { Dispersion } \\
\text { Mean absolute error (MAE) } \\
\text { Root mean squared error (RMSE) } \\
\text { Modelling Efficiency (EF) }\end{array}$ & $\begin{array}{l}0.020 \\
0.022 \\
0.510\end{array}$ & $\begin{array}{l}0.396 \\
0.512 \\
0.805\end{array}$ & $\begin{array}{c}0.017 \\
0.021 \\
-0.188\end{array}$ & $\begin{array}{l}0.500 \\
0.626 \\
0.717\end{array}$ \\
\hline $\begin{array}{l}\text { Outliers } \\
\text { Max absolute error (MaxAE) }\end{array}$ & 0.038 & 1.047 & 0.038 & 1.190 \\
\hline $\begin{array}{l}\text { Distribution } \\
\text { Variance ratio (sim/obs) } \\
\text { Kolmogorov-Smirnov test } \\
\text { Probability }\end{array}$ & $\begin{array}{l}0.959 \\
0.294 \\
0.387\end{array}$ & $\begin{array}{l}1.234 \\
0.167 \\
0.945\end{array}$ & $\begin{array}{l}1.716 \\
0.267 \\
0.589\end{array}$ & $\begin{array}{l}1.214 \\
0.111 \\
1.000\end{array}$ \\
\hline $\begin{array}{l}\text { Regression: Ysim }=\mathrm{b}_{0}+\mathrm{b}_{1} * \text { Yobs } \\
\text { Costant }\left(\mathrm{b}_{0}\right) \\
\text { Slope }\left(\mathrm{b}_{1}\right) \\
\text { Determination coefficient } \quad\left(\mathrm{R}^{2}\right)\end{array}$ & $\begin{array}{l}0.041 \\
0.742 \\
0.611\end{array}$ & $\begin{array}{l}0.235 \\
1.008 \\
0.872\end{array}$ & $\begin{array}{l}0.009 \\
0.900 \\
0.505\end{array}$ & $\begin{array}{l}0.088 \\
0.932 \\
0.758\end{array}$ \\
\hline
\end{tabular}

to obtain dose-response curves for annual irrigation water.

MiniCSS incorporates simple physiological, meteorological and agronomic knowledge that makes the application useful also for didactic purposes, enabling students to deal with the basic agronomic principles. The current version of MiniCSS has parameters for the main annual crops (maize, wheat, soybean, sunflower and sorghum).
Further crops can be implemented by the users thanks to the calibration and validation possibilities of the software. Another improvement will consist in the implementation of the energetic budget module, in order to optimize cropping systems also for the energetic efficiency. The application is freely available from the Web. 
Italy.

\section{References}

Acutis M., Perego A., Bernardoni E., Rinaldi M., 2010. AQUATER Software as a DSS for Irrigation Management in Semi-Arid Mediterranean Areas. Ital. J. Agron. 5:205-215.

Allen, R.G., Pereira, L.S., Raes, D., Smith, M., 1998. Crop evapotranspiration: guidelines for computing crop water requirements. FAO Irrigation and Drain Paper No 56, Roma, Italy.

Beck J.V., Arnold K.J., 1977. Parameter estimation in engineering and science. John Wiley and Sons, New York, NY, USA.

Bergez J.E., Deumier J.M., Lacroix B., Leroy P., Wallach D., 2002. Improving irrigation schedules by using a biophysical and a decisional model. Eur. J. Agron. 16:123-135.

Coleman K., Jenkinson D.S., 2008. RothC-26.3 A model for the turnover of carbon in soil - Model description and windows users guide. Rothamsted Research Harpenden, Herts, UK.

Danuso F., 2002. Climak: a stochastic model for weather data generation. Ital. J. Agron. 6:57-71.

Danuso F., 2003. SEMoLa: uno strumento per la modellazione degli agroecosistemi. Atti XXXV Convegno Società Italiana di Agronomia, Napoli, Italy, pp 283-284.

Danuso F., Contin M., Gani M., Giovanardi R., 1992. BIDRIC0: bilancio idrico colturale - Manuale d'uso e di riferimento. Ente Regionale per lo Sviluppo dell'Agricoltura nel Friuli-Venezia Giulia, Gorizia,
Danuso F., Franz D., Bigot L., Budoi G., 1999. CSS: a modular software for cropping system simulation. pp 287-288 in Proc. Int. Symp. Modelling cropping systems, ESA, Lleida, Spain.

Danuso F., Gani M., Giovanardi R., 1995. Field water balance: Bidrico 2. In: L.S. Pereira, B.J. van den Broek, P. Kabat and R.G. Allen (eds.) Crop-water simulation models in practice. Wageningen Pers, Wageningen, The Netherlands, pp 49-73.

Doorembos J., Kassam A.H., 1986. Yield response to water. FAO Irrigation and Drain, Paper 33, Roma, Italy.

Draper N., Smith H., 1981. Applied Regression Analysis, 2nd ed.. John Wiley and Sons, New York, NY, USA.

Forrester, J., 1961. Industrial Dynamics. Pegasus Communications, Waltham, MA, USA.

Janssen P.H.M., Heuberger P.S.C., 1995. Calibration of process oriented models. Ecol. Model. 83:55-66.

Makowski D., Walalch D., Meynard J.M., 2001. Statistical methods for predicting responses to applied nitrogen and for calculating optimal nitrogen rates. Agron. J. 93:531-539.

Muetzelfeldt R., Massheder J., 2003. The Simile visual modelling environment. Eur. J. Agron.18:345-358.

Steduto P., Hsiao T.C., Raes D., Fereres E., 2009. AquaCrop - The FAO Crop Model to Simulate Yield Response to Water: I. Concepts and Underlying Principles. Agron. J. 101:426-437. 